\title{
The Role of Risk in Targeting Payments for Environmental Services
}

\author{
Jennifer Alix-Garcia ${ }^{1}$ \\ University of Montana \\ Department of Economics \\ 32 Campus Dr \# 5472 \\ Missoula, MT 59812 \\ j.alix.garciagramail.com

\section{Alain de Janvry \\ Elisabeth Sadoulet} \\ Department of Agricultural and Resource Economics \\ University of California at Berkeley \\ 207 Giannini Hall \\ Berkeley, CA 94720
}

\begin{abstract}
This paper discusses the gain in efficiency from including deforestation risk as a targeting criterion in payments for environmental services (PES) programs. Wc contrast two payment schemes that wc simulate using data from Mexican common property forests: a flat payment scheme with a cap on allowable hectares, similar to the program implemented in several countries, and a payment that takes deforestation risk into account. We simulate the latter strategy both with and without a budget constraint. Using observed past deforestation, we find that while risk-targeted payments are far more efficient, flat payments are more egalitarian. We also consider the characteristics of communities receiving payments from both programs. We find that the risk-weighted scheme results in more, though smaller, payments to poor communities, and these payments are morc cfficient than those to non-poor ejidos. In the flat scheme, payments to poor and non-poor are equal, though they receive less of the budgct than in the more efficient program.
\end{abstract}

Keywords: Payments for environmental services, rencwable resources and conservation, market-based mechanisms, environmcntal policy, simulation, rural development

\footnotetext{
${ }^{1}$ Corrcsponding author.
} 


\section{The Role of Risk in Targeting Payments for Environmental Services}

\section{Summary}

Programs which pay for the environmental amenities provided by standing forest are becoming increasingly common. Most of the current programs, however, give the same payment for each hectare of forest enrolled, or for each hectare of different forest types enrolled up to a cap on allowable hectares. This paper discusses the gain in efficiency from including deforestation risk as a targeting criterion in payments for environmental services (PES) programs. We contrast two payment schemes that we simulate using data from Mexican common property forests: a flat payment scheme with a cap on allowable hectares, similar to the program implemented in several countries, and a payment that takes deforestation risk into account. We simulate the latter strategy both with and without a budget constraint. The program without a budget constraint is a payment of the opportunity cost for all hectares of forest which are at risk of deforestation. We use the total budget for this program as the constraint for the flat payments program, where it is assumed that recipients will not accept payments lower than their opportunity cost. In order to illustrate how to deal optimally with a budget constraint, we use $2 / 3$ of the total budget of the other programs and allocate payments according to the forests' environmental benefits/cost ratio, paying the opportunity cost for hectares at risk of deforestation. Our initial set of simulations assumes perfect foresight by using observed past deforestation, an assumption we later relax. We find that payments in our optimal program provide more than 4 times the environmental benefits for each dollar spent than in the flat program. The intuition behind this result is that a large part of the money in the flat payments program is given to forests which would have been preserved even in absence of the incentive. The tradeoff, however, is that flat payments are more egalitarian - the Gini coefficient of the flat payments is less than half that of the most efficient program. We also consider the characteristics of communities receiving payments from both programs. We find that the risk-weighted scheme results in more, though smaller, payments to poor communities, and these payments are more efficient than those to non-poor ejidos. In the flat scheme, payments to poor and non-poor are equal, though they receive less of the budget than in the more efficient program. Finally, in order to address the problem of how to avoid strategic behavior, we simulate the most efficient program using deforestation risk predicted by easily observable variables. Even with errors in prediction, the risk-targeted program is three times as efficient as a program of flat payments.

Word count for text (not including abstract, summary, references or tables): 5,579 


\section{Introduction}

Programs of payments for environmental services (PES) ${ }^{2}$ are becoming an increasingly popular way of creating, conserving, and restoring natural resources throughout the world. Mayrand and Paquin (2004) inventoried more than 300 such schemes. In recent years, PES programs have increasingly become managed by developing countries, with one of the earliest efforts occurring in Costa Rica in 1997, and pilot programs mushrooming throughout Latin America and Asia (World Bank, 2005). Payments for the conservation of standing forests are among the most numerous of such programs in developing countries. The targeting strategy in these programs has been to pay a flat fee per hectare of standing forest, where the forest owners whose forests fall in specific geographical regions voluntarily enroll hectares but where there is a limit on the number of allowable hectares. Examples of this type of targeting can be found in Mexico, Costa Rica (Zbinden and Lee, 2005), and Ecuador (Echavarrfa, 2002), among others. China's "Grain for Green" and the US Conservation Reserve programs also implement flat payment strategies, although they pay for conservation activities such as reforestation rather than standing forests (Uchida et al, 2005). The appeal of this sort of strategy clearly lies in its transparency, ease of implementation, and impression of fairness. Unfortunately, it is highly unlikely that one could find a situation in which such a scheme would maximize the environmental benefits accrued per dollar spent. Given limited budgets for conservation, the search for an efficient, readily implementable targeting scheme is imperative. In this paper we use the case of Mexico to illustrate the efficiency gain in including the risk of deforestation in the targeting criteria for payments for environmental amenities provided by standing forest.

There is a growing literature on cost effective targeting of conservation programs, much of it inspired by the US Conservation Reserve Program (Babcock et al, 1996, 1997). The main preoccupation of much of the current research is with the proper way to measure environmental

\footnotetext{
¿ Such programs are also known as programs of payments for environmental amenities, conservation payments and environmental service payments.
} 
amenities. Several economists have proposed biodiversity metrics, including Weitzman's (1998) expected genetic diversity ranking, Ando et al's (1998) total species measure, and Ferraro's (2004) distance function approach. Ferraro (2003) compares the impacts of several different index measurements for water quality benefits, and finds that all of them are highly correlated.

Our addition to this discussion is to point out that no matter what the choice of amenity measure, it is a waste of money to pay for amenities which are at no risk of being lost. Mexico provides an excellent opportunity for studying payments for services provided by forests, in large part because it is in the early stages of implementing a nationwide PES program for standing forest. Presently, $80 \%$ of the country's forests are located in ejidos. These communities, which were created by the post-Revolution land reform, hold their forestry and grazing lands in common property. Their large share of national forest holdings makes them an essential place where to begin addressing the deforestation problem.

Using data obtained from a 2002 ejido survey, we compare two targeting strategies for payments. The benchmark case is a payment per hectare with a cap on allowable hectares. We compare this design to a program which incorporates deforestation risk, showing how risk-targeted payments might be distributed with and without a budget constraint. In the former situation, payments of the opportunity cost are given only for those hectares of forest that are at risk of deforestation. The total budget of this program is used to provide a point of comparison for the other two programs. First, the magnitude of the flat payments is established in order to give the same total expenditures as in the opportunity cost program. Second, two-thirds of this budget gives the constraint for the final program, in which payments are distributed in order to maximize the environmental benefits per dollar spent.

The main result of these simulations is that while the benchmark scheme is very egalitarian, it is highly inefficient. The unconstrained risk-targeted program generates more than three times the 
environmental benefits at the same cost as the flat payments program. Simulation of the program which maximizes the environmental benefits per dollar spent increases efficiency over the flat payments program by over four dmes. The intuition behind the result is simple: paying everyone to preserve their forest may achieve the goal of income redistribution, but at a high cost — much of the payments will go to forests which even in the absence of incentive schemes would remain standing. We also illustrate how to avoid strategic behavior on the part of recipients by conducting a final simulation which uses the predicted rather than actual risk to implement the last program, we find that there are errors in targeting, but that efficiency is still much greater than in a flat payments program.

Since policymaking is both about efficiency and equity, we also analyze the distributional impacts of the first and the last schemes that we consider. The results show that the budget from the flat payments program is more equitably distributed amongst ejidos of different size and poverty classes, while the optimal program allocates more funds to larger and poorer communities. The optimal program, however, gives smaller payments to poor ejidos on a per capita basis, while flat payments per capita are equal for the poor and non-poor.

The paper proceeds as follows: we first describe the theoretical considerations behind the different targeting strategies we consider, which leads us to the empirical strategy discussed in section 3. Section 4 describes the data to be used for the simulations and section 5 gives the results. Section 6 discusses some practical considerations for the implementation of our most efficient strategy and the last section concludes.

\section{Alternative payment schemes - theoretical considerations}

There are many possible ways of designing an environmental payment scheme. Any variation in design will change the kind of environmental services obtained and the people who receive payments. Conceptually, there are an upper and a lower bound on the "prices" which one can pay per hectare in a 
PES program: the opportunity cost of the land and the value of the environmental services provided by the land. In this section we discuss some principles that apply regardless of the program design chosen.

\section{Basicprinciples}

Two criteria essential for the establishment of a PES program are targeting and the magnitude of the payments. In theory, these should be jointly defined to maximize environmental benefits for a given budget and therefore the optimal scheme depends upon the response function of the tecipients, in this case, the ejidos. To formalize, let $U\left(F_{e}-\Delta F_{t}, c_{t} \Delta F_{e} ; z_{e}\right)$ be the utility an ejido $e$ derives from the standing forest, $F_{e}-\Delta F_{e}$, and the income generated by deforesting a quantity $\Delta F_{e}$, where $c_{e}$ is its opportunity cost per hectare and $z_{\epsilon}$ are ejido characteristics. The optimal deforestation level is thus a function of the initial standing forest, the opportunity cost, and the ejido characteristics:

$$
\Delta \tilde{F}_{e}=\Delta F\left(F_{e}, c_{e}, z_{\ell}\right)
$$

The offer from the PES program is to not deforest at all against a total payment of $P_{e}$. The ejido will thus accept the contract if:

$$
U\left(F_{e}, P_{e} ; z_{e}\right) \geq U\left(F_{e}-\Delta \tilde{F}_{e}, c, \Delta \tilde{F}_{e} ; z_{\ell}\right)
$$

Let $P_{e, \text { min }}$ be the minimum value that satisfies this condition. Given the environmental benefit $b_{e}$ provided per hectare in ejido $e$, the optimal transfer scheme under the budget constraint $\bar{P}$ is the solution to:

$$
\begin{array}{ll} 
& \max _{P_{e} \sum_{e}} \sum_{e}\left[P_{e} \geq P_{e, \min }\right] \Delta F\left(F_{e}, c_{e}, z_{e}\right) b_{e} \\
\text { s.t. } \quad & \sum_{e} 1\left[P_{e} \geq P_{e, \min }\right] P_{e} \leq \bar{P} .
\end{array}
$$

Ideally, one would like to know the monetary value equivalent to the utility that ejidos derive from standing forest. In the absence of such valuation, one can use $P_{e, \text { mir }}=c_{e} \Delta \bar{F}_{e}$ as an lower bound for the 
acceptability of the scheme to the ejido (this is equivalent to ignoring the loss in utility associatcd with the decrease in standing forest). Ejidos accept the payment and agrec to not deforest if the payment $P_{e}$ is at least as high as the opportunity cost of converting the land into pasture/crops, and do not accept the contract if the offered payment is below the opportunity cost:

$$
\begin{aligned}
& \text { If } P_{e} \geq c_{e} \Delta F\left(F_{e}, c_{e}, z_{e}\right) \Rightarrow \Delta \tilde{F}_{e}=0 \\
& \text { If } P_{e}<c_{e} \Delta F\left(F_{e}, c_{e}, z_{e}\right) \Rightarrow \Delta \tilde{F}_{e}=\Delta F\left(F_{e}, c_{e}, z_{e}\right) .
\end{aligned}
$$

The question that follows is: should one pay the minimum value necessary to preserve the environmental benefits, i.e., the opportunity $\operatorname{cost} c_{e}$ of the land, or the entirc valuc of the good being purchased, i.e., the environmental benefit $b_{e}$ ? In reality, this is a question of property rights. In both cases, payments can only be socially justified if the benefits offered by the land arc greatcr than or equal to the value of the land in alternative activities, $b_{e} \geq c_{e}$.

If one looks at the formulac above, the optimal contract only pays for the hectares that would otherwise be deforested, $\Delta \Gamma\left(\Gamma_{e}, c_{e}, z_{e}\right)$, which varies with the deforestation rate. In actuality, one frequently observes a flat payment per hectare of currently standing forest $F_{\varepsilon}$ with a cap. In many places, this payment varies with quality of forest in terms of bencfits, but the point here is that it does not depend on the deforestation rate. An argument in favor of this flat payment is the simplicity of implementation and the impression of fairness that it gives, as it docs not takc into account dcforestation bchavior.

Regardless of the choice of targeting scheme, the contract must be made over the entire area of the cjido. Neglecting this consideration could lead to "slippage" (a term coined by Wu (2000)), that is, if a contract is incomplete, then deforestation may simply be transferred from a contracted to an uncontracted area of forest. Hence, typically, the contract should specify a payment against no deforestation on all of the hectares that have an opportunity cost below their environmental benefits. 


\section{Proposed simulations}

In this section we specify the alternative payment schemes that will be simulated. Building from our theoretical considerations, we have selected 3 payment schemes:

1. A flat payment over all hectares with a cap with the objective of simulating a scheme similar to those observed $[\mathrm{F}]$.

2. A payment for all hectares at risk of deforestation at their opportunity cost $[R c]$ without a budget constraint. The total budget of this program provides the constraint for $[\mathrm{F}]$, where payments are set at a rate that gives the same aggregate budget as $\mathrm{Rc}$,

3. A targeting that maximizes environmental benefits per dollar paid using an index of environmental benefits (as opposed to actual benefits in dollar terms) and a payment at opportunity cost for each hectare at risk, for a given budget (here arbitrarily set at $2 / 3$ of the budget of the first scheme to illustrate how the budget constraint could be optimally dealt with) [C].

Flat payment, F

We here assuflat payment of $r$ per hectare, up to a maximum of $\bar{F}$ hectares: $P_{e, F}=r \min \left[\sum_{j} F_{g}, \bar{F}\right]$.

$P_{e, F}$ is the total payment to ejido $e$, which is the rate per hectare multiplied by cither the sum of forest hectares of type $j$ or by the maximum allowable hectarcs. Assume that there is a constant deforestation rate $\tau_{i j}$ of forest of category $j$ in the ejido, and that the opportunity cost of a hectare of land in the ejido is $c_{,}$. All ejidos are offered a contract, but an ejido will only accept the contract and 
thus participate in the scheme if the opportunity cost of the area it would otherwise deforest is less than the offer: $\quad P_{e, F} \geq \sum_{j} c_{e} \tau_{g j} F_{g j}=P_{e, \mathrm{R} r}$

In order to facilitate comparison of the schemes, the rate $r$ is established at the lcvel that equalizes the total budget to the budget of the scheme $R c$, which pays the opportunity cost for each hectare of land at risk of deforestation and will be detailed in the next section. It thus solves for:

$$
\sum_{e} 1\left[P_{e, F} \geq P_{e, R c}\right] P_{e, r}=\sum_{e} P_{e, R c}
$$

Rental of bectares at risk, $R_{\text {c }}$

We allow for heterogeneity of environmental benefits within ejidos. Each hectare of forest is characterized by an environmental benefit $b_{j}$. Ideally, one would prefer an actual monetary value for the environmental benefits offered by a given piece of land. In reality, however, this is quite difficult to establish, as markets are missing for these services. So, for the purpose of our simulations, we establish an index value $b_{j}$ that allows the ranking of each hectare of forest by its relative environmental value. Note that this does not allow us to exclude lands whose true environmental value is less than the opportunity cost.

Let $F_{g j}$ bc the number of hectares with environmental benefits $b_{j}$ in ejido $e$, with $\sum_{j} F_{e j}=F_{e}$ the total forest area in ejido $e$. The first year of the program, the unchallenged deforestation would convert $\tau_{b j} F_{g j}$ of forest of quality $j$ into pasture. The second year, an additional $\tau_{i j}$ of the remaining forest $\left(1-\tau_{g j}\right) F_{g}$ would be converted, and similarly the following ycars. The deforested area after $t$ years would thus be:

$$
\Delta F_{g j}^{t}=\left(1-\left(1-\tau_{g j}\right)^{t}\right) F_{g j}
$$


If the program is to prevent deforestation over the years, it should thus "rent" an increasing share of the forest. Payments based on the opportunity cost, assuming that the environmental benefits of all hectares exceed the cost, would bc: $p_{e, \mathrm{R} c}^{t}=\sum_{j} c_{e} \Delta F_{g j}^{t} \quad$ Because we are paying exactly their opportunity cost for the hectares of land they wish to deforest, ejidos will always accept the contract. The participating ejidos are those that would otherwise deforest. Note that the contract is for no deforestation on the total initial ejido area with opportunity cost below environmental benefits. Hence the area enrolled in the contract is $\sum_{j} F_{g}$. Environmental benefits obtained by contracts in the participating ejidos are: $B_{e, R_{f}}^{t}=\sum_{j} b_{j} \Delta F_{i j}^{t}$. In the rest of the paper, since we are only concerned with comparing programs, we will only consider the first year of payment, and leave out the $t$ superscript. Assuming that all communities have a fixed deforestation rate, or that any changes in the rate occur equally for all communities, calculating program outcomes for the first year will give us the same relative rcsults for payment schemes that depend upon deforestation risk.

Note that by restricting ourselves to the first year of payments we are showing the flat payment scheme in the best possible light. That is to say, since the flat payments do not change over time and the opportunity cost does, the first year gives the maximum number of communities that will accept the payments at any given time.

\section{Constrained program, $C$}

If the total payment $\sum_{e} P_{e, \mathrm{R} c}$ exceeds the available budget, the optimal scheme consists of ranking the ejidos by dccreasing ratio of benefits over cost: $\quad b_{e}=\frac{\sum_{j} b_{j} \tau_{g i} F_{i j}}{\sum_{j} c_{e} \tau_{g j} F_{g j}}$ and paying the opportunity cost of 
the hectares at risk of deforestation $P_{e, C}=P_{e, R c}=\sum_{j} r_{e} \tau_{g j} F_{g j}$ to those with the highest ratio until the budget is exhausted.

\section{Description of the Data}

In the summer of 2002, Mexico's National Ecology Institute (INE), together with the Iberoamericana University, the Center for Economic Education and Research (CIDE), the University of California at Bcrkeley, and the World Bank, conducted a survey of Mcxican ejidos. The purpose of the survey was to understand the deforestation process in these communities in order to inform the design of a PES program ${ }^{3}$ that the Mexican government was interested in introducing. The survey randomly sampled 407 ejidos larger than 100 hectares located in the forested regions of the country. The total universe of ejidos with forest over 100 hectares is 7,679. The total amount of forest covered by our sample is $2,106,592$ hectares of primary and secondary forest. Table 1 shows the distribution of communities across regions.

The sample included ejidos in all states with the exception of Baja California, Coahuila, Guanajuato, Zacatecas, Morelos, and Aguascalicntes. In order to measure forest cover and its change over time, we use the Forest Inventories for 1994 and 2000, which were constructed by visual interpretation from satellite images with pixels of 30 meters at a scale of 1:250,000 (Velázquez et al., 2002). In addition, we obtain slopes from digital clcvation models with 100 meter pixels available from the Mexican government.

Overall, $86 \%$ of the ejidos in our sample currently have primary forest. The area of primary forests is largely related to ejido size, which varies considcrably across ejidos. Total ejido area ranges from 180 to 170,143 hectares in our sample. The average percentage of a given ejido in primary forest is $34.7 \%$. On a per capita basis, the distribution of the forest is quite skewed. Though the average number of

\footnotetext{
${ }^{3}$ This program was effectively introduced in 2003.
} 
hectares per capita is 37 , the median is 6.5 and the Gini coefficient .83 . This suggests that any payment program disbursed on a per hectare basis will be similarly unequal in its distribution across communities and individual members.

The deforestation rate over the total forest in our sample is $1.2 \%$ per year from 1994 to 2000, which is comparable to what Torres and Flores (2001) term the "conservative estimate" of $1.3 \%$ per year. In our sample, the average ejido deforested about 1.3\% per year over the period $1994-2000.61 \%$ of the ejidos in the sample deforested over the study period, where deforestation is defined as the change from primary or secondary forest to agriculture or pasture. Amongst those who deforest, the average rate of forest loss is $2.1 \%$ per year.

\section{Empirical results}

\section{Calculation of the cost}

In order to measure the opportunity cost of forested land, we use the rainfed land rental rates reported in the 2002 ejido survey. Because ejido land cannot actually be rented, the numbers reported were the farmers' assessment of the land rental rate for a piece of land similar to the one that had been deforested. These rates were observed for those ejidos that experienced deforestation and refer to areas from which they had removed forest between 1994 and 2000. We consider this rate to be a fair estimate of the opportunity cost of the land that is most likely to be deforested, although it is likely not as accurate for the more remote areas of the ejido. Because this rate was not reported for some ejidos, we use as a measure of the opportunity cost the value of the rental rate predicted by the regression equation in table 2. The average rental rate is $\$ 103$ US (sd $\$ 70$ ) and the Gini coefficient of the per hectare rate is .37 .

\section{Calculation of the environmental benefits index}


Ideally, $b_{j}$ should be expressed in monetary terms. This requires use of a valuation technique for services whose markets fail, or one of the techniques advocated by the authors mentioned in the introduction. For services where markets exist, such as hydrological benefits, values remain highly debated, with estimates ranging from $\$ 20 /$ ha (Chomitz et al, 1998) to $\$ 188$ (Hernández, et al., 2003). Still other studies suggest that a mixture of pasture and forest cover generates even higher hydrological benefits that contiguous forest (Aylward and Tognetti, 2002). Hesitant to enter into this valuation debate, we have instead established an environmental index based upon both the scale of payments for the existing PES scheme in Mexico and the country's environmental priorities. Mexico's current payment program, which gives higher payments for cloud forests as opposed to forests of other types, is intended to reflect the higher hydrological value of the cloud forests. While changing the measure of benefits will change the distribution of payments, the main result of our study, that it is more efficient to pay for benefits which are at risk of being lost, will not change.

Mexico's PES program is intended to preserve the hydrological benefits provided by standing forcst. Wc therefore design a simple index which reflects this objective as follows. Forests that are closer to major rivers are given a higher value than forests that do not have this attribute. Because a detailed river map of the country is not available, we used digital elevation models to establish where the highest flow of water across the landscape would be. Around areas of high flow, we calculated a buffer distance of one kilometer as the area whose erosion would most affect water quality and infiltration, and gave higher value to forcsts in these areas. In addition, we give higher values to those communities located in watersheds which have been classified as over-exploited. Over-exploited watersheds have been identified and mapped by INE. Finally, given that cloud forest is of particular concern because of its status as an endangered ecosystem in Mexico and is thought to produce a higher value of water services, we give them extra points as well. This differential reflects the price differential in the PES program as it is currently being implemented in Mexico - payments per hectare for cloud 
forests are 400 pesos, while for other types of forest they are 300. The current program was designed for payments to reflect the higher environmental value of cloud forest for water conservation. All forest types were defined according to the classification in the 2000 Forest Inventory.

Table 3 describes the values that we use for ranking the environmental benefits provided by different types of forest in different locations. The average benefits per hectare are 30.6 points (sd 5.3) and the Gini coefficient is .11.

\section{Payments andparticipation}

To compare the payment schemes, we begin by assuming perfect foresight in predicting deforestation by using the observed deforestation rate between 1993 and 2000 . We will relax this assumption in section 6 by using a predictive equation for deforestation in discussing implementation of the optimal scheme. We simulate the three schemes as if they were put into place in 1994 and we are observing the results one year later. The results are reported in tables 4 and 5 . The flat payment ended up being $\$ 5$ per hectare with the opportunity costs budget as a constraint. In the first payment program, all of the deforesting ejidos (61\% of the sample) are paid in 1994, though the payments are quite unequally distributed, with a Gini coefficient of .81. In the flat payment program, the participation rate is much higher, at 87 percent, due to the fact that many ejidos without deforestation participate, though we do lose some of the deforesters with an opportunity cost higher than the flat payment offer. The distribution of these payments is much more equitable, with a Gini of .32 . In the optimal constrained program, where we use $2 / 3$ the budget of the first program, we have less than $2 / 3$

participation (57\%) and a Gini coefficient of 0.77 , indicating the high inequality of payment distribution.

Table 5 highlights the tradeoffs that exist between the inequality of the second and third programs and their efficiency. The total number of hectares deforested in the sample between 1994 
and 2000 is 22,667, which is the amount enrolled in the opportunity cost program. Despite its higher participation, the flat payments program enrolls less than a third of the total hectares at risk of deforestation, 6,732 hectares, and the amount of environmental benefits per dollar spent, at .08, is also less than a third of that of the opportunity costs program. This is due to the fact that it enrolls many ejidos that do not have positive deforestation. The optimal distribution of the constrained budget, shown in column three, results in the enrollment of 19,225 hectares, which is nearly all of those at risk and an efficiency level of .35 , four times higher than that of the flat payments scheme.

Table 6 illustrates another measure of efficiency — the dollar amount paid for each hectare at risk of deforestation. Note that this is extremely large for the flat payment scheme (despite the fact that those with zero deforestation cannot be included) at $\$ 7,610$ per hectare and smallest for the optimal strategy, which pays $\$ 86$ per hectare on average. This very high number from the flat payments results from the fact that a very high price is paid for hectares that have a very low risk of deforestation. This is effectively a form of leakage of program funds to non-critical forests.

Whogets the payments?

In this section we examine the distribution of both the flat payments program and the most efficient payment program over different structural and social characteristics of participants. Table 7 shows the distribution of the flat payments program and the most efficient payments over size and poverty classes. In the case of the payments by poverty class, we consider per capita receipts rather than total payments. This is calculated under the assumption that payments at the community level will be shared equally between members. Participation in the flat program is much higher in all area classes, while it increases across classes in the optimal constrained program. This is due to the fact that deforestation in larger communities is higher. Efficiency, which is relatively constant across 
distance classes in the optimal case, is increasing with area in the flat payments program because as the properties get larger, the flat payments program is more likely to enroll hectares at risk of deforestation. We see an interesting result with regards to equity. Although participation in both programs is higher for the poor than it is for the non-poor, it is relatively greater in the optimal program - 63 versus $50 \%-$ than it is in the flat payments program -89 versus $85 \%$. In addition, the optimal program allocates a greater share of the budget to the poor -61 as opposed to $54 \%$. At an individual level, however, we find that payments per capita to the poor, $\$ 51$, are much lower than to the non-poor, who receive $\$ 135$ per capita. This is likely the result of the smaller endowments of environmentally valuable resources among poorer and indigenous ejidos, which are also likely to have more members among which to divide the payments.

\section{Implementation with predicted deforestation rate, I}

In order to implement payment schemes which take deforestation risk into account, it is necessary to use the predicted rather than the actual deforestation rate. Using the actual deforestation to predict hectares at risk would induce strategic behavior on the part of ejidos. This section focuses on the application of two predictions of the deforcstation rate to the most efficient program. Whatever prediction is chosen, it must be based exclusively on determinants $x$, that are truly exogenous to the behavior of the ejido (so that the scheme does not reward bad behavior), i.e., physical endowments of the ejido (area of different types of land, maybe on per capita basis), and structural characteristics such as distance, population, ethnicity, etc. We assume a uniform deforestation rate per ejido (i.e., all categories $j$ of forest have the same deforestation rate $\tau_{\varepsilon}$ ), and perform the estimation on the observed sample of ejidos. Although this estimation gives prediction of the expected conditional deforestation

rate $\hat{\tau}\left(x_{e}\right)$ in the population of ejidos of characteristic $x_{e}$, the actual optimal rate of deforestation of a 
specific ejido $e$ remains unknown to outsiders: $\hat{\hat{\tau}}_{e}=\hat{\tau}\left(x_{e}\right)+u_{e}$, where $u_{\text {, }}$ represent the idiosyncratic shock or behavior of the ejido, drawn from the estimated distribution $N\left(0, \hat{\sigma}^{2}\right)$.

Armed with this analysis, we simulate the most efficient scheme based on the predicted deforestation rate $\hat{\tau}$, as follows: We first rank ejidos by decreasing ratio of environmental benefits over opportunity cost (which is independent of the deforestation tate), as we did above. We then pay the predicted conditional expected deforestation $\hat{\tau}_{e} F_{g j}$ proportionately to the expected opportunity cost $P_{e, l}=\sum_{j} c_{e}(1+\mu) \hat{\tau}_{e} F_{g j}$ starting with those with the highest ratio until the budget $\bar{P}$ is exhausted.

A specific ejido will accept the scheme if the payment compares favorably to the opportunity cost of its optimal deforestation rate, i.e., if: $P_{e, l} \geq \sum_{j} c_{e}\left(\hat{\tau}_{e}+u_{e}\right) F_{g}$ which can also be written: $\hat{\tau}_{e}+u_{e} \leq(1+\mu) \hat{\tau}_{e}$. This shows that if the payment is set at the expected opportunity cost, i.e., $\mu=0$, all the ejidos with higher deforestation rates than the average will not accept the contract. Conversely, all ejidos with predicted rates lower than the averagc are compensated for their "good" behavior. By proposing a higher payment, $\mu>0$, the program faces a trade-off in paying more than necessary for many ejidos but attracting more of them into the scheme. It follows that the optimal value for the payment level $\mu$ is determined by the overall optimization program:

$$
\begin{array}{ll}
\max _{P_{e}} \sum_{e} \operatorname{Pr}\left[u_{e} \leq \mu \hat{\tau}_{e}\right] \sum_{j} b_{j}\left(\hat{\tau}_{e}+E\left(u_{e} \mid u_{e} \leq \mu \hat{\tau}_{e}\right)\right) F_{g} \\
\text { s.t. } & \sum_{e} \operatorname{Pr}\left[u_{e} \leq \mu \hat{\tau}_{e}\right] P_{e, I} \leq \bar{P} .
\end{array}
$$

\section{Two prediction equations}

We present in table 8 two different prediction equations for deforcstation. The first is a parsimonious specification, containing only easily observable, mostly physical variables, while the second includes a range of vatiables associated with deforestation behavior in common property 
communities (see Alix-Garcia, de Janvry, and Sadoulet; 2005). The former represents a technique suitable for application in policy settings. The intention of presenting both options is to see how much targeting precision is lost in omitting variables representing community behavior.

The first estimation includes total ejido arca, forest area, forest squared and forest cubed, the average distance to, slope and altitude of the forested area of the ejido, interactions of these terms, a dummy for if the ejido practices forestry or not, and the number of ejido members in 1990 . None of these variables is easily changed by community members. Among these variables, the largest impacts on deforestation are through the size of the forest in 1994, the average slope of the forested area, and if the ejido practices forestry or not. The second specification includes, in addition to the physical variables, some characteristics that might influence group behavior, such as the number of people per household with secondary education, average size of individual parcels, the Gini coefficient of the distribution of private parcels, the ratio of member to total population in the ejido, and the predicted proportion of the population receiving Progresa - an educational subsidy program distributed to the poor. The largest impacts come from the Gini coefficient and the predicted proportion of the population receiving Progresa. The second specification shows a small gain in the regression adjusted R-squared over the parsimonious specification - from .38 to .42 . This suggests that the second specification has superior predictive power over the first. In general, however, an R-squared of .38 is quite respectable for such a cross-sectional estimation.

Since there is not much gain from the cxpansion of the variable set in (2), Table 9 shows the payments calculated using only the parsimonious (1) specification. The efficiency level is considerably lower than that of the most efficient program using the actual deforestation rates, at .35 , but is still twice as efficient as the flat payments'.08. As in the actual program, the Gini coefficient of payments for the predicted program is considerably higher than that of the flat payments program, which has a value of .32 . 
This leads us to the question of where the misallocation of payments occurs. Table 10 shows the characteristics of communities with payments in different error categories. The type II error comes entirely from deforestation rates that are estimated to be positive for ejidos that in reality had no deforestation. These communities also have very high benefits and low opportunity costs, which means they ranked quite high on our benefits to cost scale. Communities with type I error have very high deforestation rates (and were under-predicted). In addition, their opportunity costs are large relative to the benefits that their land provides.

In sum, the more worrying type I error comes from ejidos with very high opportunity costs and very high rates of deforestation. These are also communities with somewhat low environmental benefits per hectare. In avoiding the strategic behavior associated with using observed deforestation rates, we end up with a lower level of environmental benefits per dollar spent, though this is still nearly twice as high as the efficiency level generated by using a flat payments program.

\section{Conclusion}

The most important contribution of this paper is to point out that including risk into the targeting of environmental services programs can great increase their efficiency. We illustrate this point by comparing a flat payment scheme to a scheme which takes into account the risk of deforestation. We simulate three programs: a flat payment scheme, a payment of opportunity cost for each hectare of forest at risk of deforestation, and, in order to illustrate the optimal manner of dealing with a budget constraint, a program which distributes payments according to the highest benefit/cost ratio and pays the opportunity cost for each hectare of forest at risk of deforestation. Comparing these approaches, we find that the most egalitarian approach is to pay a flat rate per hectare per year but to cap the number of allowable hectares. This is also the least efficient strategy in terms of environmental benefit per dollar spent. The highest efficiency comes from maximizing environmental benefits per 
dollar spent. The driving force behind these results is the leakage inherent in ignoring deforestation risk in the targeting process — in a program which gives the same payment for any hectare of forest very high prices are paid to conserve hectares of forest that were at no risk of being lost in the first place.

When we consider the distribution of payments of the flat and efficient programs according to characteristics of recipient communities, we find that in the case of the efficient program, larger and receive the lion's share of the budget, although they are not always the most efficient in providing environmental services. We also find that have higher participation rates, get a larger proportion of the budget and provide higher benefits per dollar spent that non-poor ejidos. In the optimal program, payments per member to the poor and indigenous are much lower than to their counterparts, reflecting the fact that environmentally valuable resources per capita are higher among the non-poor and nonindigenous. In the more egalitarian flat scheme, the budget is distributed relatively equally across size, and poverty classes, and payments to the poor and non-poor are equal.

Finally, we also address one of the important factors in implementing a scheme which accounts for deforestation risk. In order to avoid strategic behavior, one must use predicted deforestation using non-manipulable variables. We show that there is little advantage in venturing beyond easily observable variables in order to make this prediction. There is an efficiency loss in using the prediction as opposed to the actual rate of forest loss, but a program using the predicted deforestation rate is still twice as efficient as a flat payment program.

\section{Works Cited}

Alix-Garcia, de Janvry, and Sadoulet (2005) "A Tale of Two Communities: Explaining Deforestation in Mexico" World Development 33(2): 219-235.

Ando, A., Camm, J , Polasky, S. and Solow, A. (1998) "Species Distributions, Land Values, and Efficient Conservation" Science 279: 2126-8. 
Aylward, B. and Tognetti, S. (2002) "Valuation of hydrological externalities of land use change: Lake Arenal case study, Costa Rica" Land-water linkages in rural watersheds, Case study series. FAO, Rome.

Babcock B.A., Lakshminarayan, P.G., Wu, J. and Zilberman, D. (1996) "The Economics of a Public Fund for Environmental Amenities: A Study of CRP Contracts" American Journal of Agricultural Economics 78: 961-971

Babcock B.A., Lakshminarayan, P.G., Wu, J. and Zilberman, D. (1997) "Targeting Tools for the Purchase of Environmental Amenities." Land Economics 73 :325-39.

Chomitz, K., Brenes, E., and Constantino, L. (1998) "Financing Environmental Services: The Costa Rican Experience and its Implications" Paper prepared for the Environmentally and Socially Sustainable Development, Latin America and Caribbean Region, World Bank.

CNF, Comisión Nacional Forestal, Semarnat/Conafor (2001) Programa Nacional Forestal 2001-2006.

Dupaz, P. (2003) "The Environmental Supply of Farm Households: A Flexible Willingness to Accept Model" Environmental and Resource Economics 25 (2): 171-189.

Ferraro, P.J. (2003) "Conservation Contracting in Heterogeneous Landscapes: An Application to Watershed Protection with Threshold Constraints." Agricultural and Resource Economics Reviezy 32(2003): 53--64.

Ferrato, P.J. (2004) "Targeting Conservation Payments in Heterogeneous Landscapes: A Distance Function Approach and Application to Watershed Management" American Joumal of Agricultural Economics 86(4): 905-918.

FIA (2003) Web site of the International Automotive Federation "Down Mexico Way" http://urww.tia.com/Automotive/Automotive/summer\%201997/p5.html downloaded 7/19/03

Hernández, O., Cobos, C., Ortiz, A. and Méndez, J.C. (2003) 'Valoración Económica del Servicio Ambiental de Regulación Hidrica del Lado Sur de la Reserva de la Biosfera Sierra de las Minas, Guatemala". Paper prepared for Foro Regional sobre Sistemas de Pago por Servicios Ambientales. Aréquipa, Peru.

Mayrand, Karcl and Paquin, Marc (2004) Payments for Environmental Services: A Survey and Assessment of Current Schemes Unisfera International Center (for the Commission for Environmental Cooperation of North America) http://www.cec.org/files/PDF/ECONOMY/PES-Unisfera_en.pdf

.Muñoz et al (2003) "Opportunity Cost Estimation of Forest Land Use in Mexican Commons" Instituto Nacional de Ecología, Dirección General de Investigación en Política y Economía Ambiental.

Pagiola, S., Bishop, and J. Mills, N., eds. (2002) Selling Forest Environmental Services: Market-based Mechanisms for Conservation and Development Earthscan Publications, London.

Parks, P. and Schorr, J. (1997) "Sustaining Open Space Benefits in the Northeast: An Evaluation of the Conservation Reserve Program" Joumal of Environmental Economics and Management 32 (1): 85-94. 
Ribaudo, Marc (1989) "Targeting the Conservation Reserve Program to Maximize Water Quality Benefits." Land-Economics 65(4): 320-32.

SEMARNAT (2003) "Reciben Productores Forestal Pago por Servicios Ambientales, por Vez Primera cn el Pais" Comunicado de Prensa Núm. 012/03. Xalapa, Ver. February 18, 2003

http://www.semarnat.gob.mx/comunicacionsocial/boletines $2003 \quad 012 . s h t m l$ downloaded 7/19/03.

Torres-Rojo, J.M. and R. Flores-Xolocotzi. (2001) "Deforestation and Land Use Change in Mexico" in Climate Change and Forest Management in the Western Hemisphere Haworth Press, Inc.

Velázquez, A., Mas, J. y Palacio, J. Análisis del cambio de uso del suelo Convenio INE-IGg (UNAM) (Oficio de autorización de inversión 312.A.-00215, Instituto de Geografía, UNAM, Enero

Weitzman, M.L. (1998) "The Noah's Ark Problem." Econometrica 66:1279-98.

World Bank (2003) "Payments for Ecological Services" Web page of Environmental Economics and Indicators.

http://nweb18.worldbank.org/ESSD/essdext.nsf/44DocByUnid/1938A989CDB7F9C385256B5000 63D62D? Opendocument.

World Bank (2005) Current World Bank Work on Payments for Ecological Services. http://lnweb18.worldbank.org/ESSD/envext.nst/44ByDocName/PaymentsforEcologicalServicesCur rentProjects

Wu, J. (2000) "Slippage Effects of the Conservation Reserve Program" American Joumal of Agricultural Economics, 82(4): 979-92.

Uchida, E., Xu, J., and Rozelle, S. (2005) "Grain for Green: Cost-cffectiveness and Sustainability of China's Conservation Set-Aside Program" Land Economics 81(2): 247-264.

Zbinden, S. and Lce, D. (2005) "Paying for Environmental Services: An Analysis of Participation in Costa Rica's PSA Program" World Development 33(2): 255-272. 
10 Tables

Table 1. Distribution of forest ejido universe by region*

\begin{tabular}{|c|c|c|c|c|}
\hline Region & Ejidos & population & Sample & $\begin{array}{c}\% \text { of } \\
\text { sample }\end{array}$ \\
\hline Peninsula & 745 & 9.7 & 39 & 10.0 \\
\hline Gulf & 795 & 10.4 & 37 & 9.5 \\
\hline South & 2,152 & 28.0 & 110 & 26.8 \\
\hline Central & 2,488 & 32.4 & 122 & 29.6 \\
\hline North & 1,499 & 19.5 & 99 & 24.2 \\
\hline Total & 7,679 & 100 & 407 & 100 \\
\hline \multicolumn{5}{|c|}{$\begin{array}{l}\text { Table 2. Prediction of Rainfed Land Rental Rate } \\
\text { Dependent Variable: Dollars per hectare of land per year }\end{array}$} \\
\hline Variable & & Coeffic & ent & T-statistic \\
\hline $\begin{array}{l}\text { Average distan } \\
\text { forest in } \mathrm{km}\end{array}$ & om village to & -48 & & 1.7 \\
\hline Average distan & uared & 2.1 & & 1.5 \\
\hline $\begin{array}{l}\text { Average altitu } \\
\text { meters }\end{array}$ & of forest in & -.13 & & 1.3 \\
\hline Average slope & rest & 10.8 & & 1.1 \\
\hline Distance*slope & & -.45 & & .53 \\
\hline Distance* altitu & & .02 & & 1.3 \\
\hline Total size in 10 & & 1.2 & & 3.7 \\
\hline State level maiz & ld per ha & 68 & & 2.2 \\
\hline Yield*slope & & -4.3 & & 1.5 \\
\hline Yield*altitude & & -.02 & & 1.3 \\
\hline $\begin{array}{l}\text { Distance to } \\
\text { kilometers }\end{array}$ & est town in & -.17 & & .88 \\
\hline Constant & & 237 & & 1.5 \\
\hline Observations & & 91 & & \\
\hline R-Squared & & .23 & & \\
\hline
\end{tabular}


Table 3. Constructing an environmental index

\begin{tabular}{|c|c|}
\hline Characteristic & $\begin{array}{c}\text { Points per } \\
\text { hectare }\end{array}$ \\
\hline \multicolumn{2}{|l|}{ Cloud forest } \\
\hline Primary & 40 \\
\hline Secondary & 30 \\
\hline \multicolumn{2}{|l|}{ Other types of forest } \\
\hline Primary & 30 \\
\hline Secondary & 20 \\
\hline \multicolumn{2}{|l|}{$\begin{array}{l}\text { Added to each hectare of } \\
\text { above: }\end{array}$} \\
\hline Overexploited watershed & 5 \\
\hline \multicolumn{2}{|l|}{ Within _ mile of a river } \\
\hline Primary & 20 \\
\hline Secondary & 10 \\
\hline
\end{tabular}

Table 4. Summary of payments and participants in different programs

\begin{tabular}{lccc}
\hline Payment rule & $\begin{array}{c}\text { Flat payment } \\
\text { with a cap at } \\
2000 \text { ha }\end{array}$ & $\begin{array}{c}\text { Opportunity } \\
\text { cost for forest } \\
\text { at risk }\end{array}$ & $\begin{array}{c}\text { Opportunity cost for } \\
\text { forest at risk with } \\
\text { highest } \\
\text { environmental } \\
\text { benefit per } \$ \text { paid }\end{array}$ \\
\hline $\begin{array}{l}\text { Percent of ejidos } \\
\text { enrolled }\end{array}$ & 87 & 61 & $C$ \\
$\begin{array}{l}\text { Average payment per } \\
\text { participating ejido }\end{array}$ & $\$ 7,341$ & $\$ 10,202$ & 57 \\
$\begin{array}{l}\text { Median payment per } \\
\text { participating ejido }\end{array}$ & $\$ 7,234$ & $\$ 1,744$ & $\$ 1,418$ \\
$\begin{array}{l}\text { Gini coefficient of } \\
\text { payments over } \\
\text { participants }\end{array}$ & .32 & .81 & \\
\hline
\end{tabular}


Table 5. Costs and benefits of different payment programs

\begin{tabular}{lccc}
\hline Payment rule & Flat payment & $\begin{array}{c}\text { Opportunity } \\
\text { cost for forest } \\
\text { at risk }\end{array}$ & $\begin{array}{c}\text { Opportunity cost for } \\
\text { forest at risk with } \\
\text { highest environmental } \\
\text { benefit per opportunity } \\
\text { cost } \\
C\end{array}$ \\
\hline Total hectares enrolled & $1,022,133$ & $1,836,535$ & $1,534,405$ \\
Hectares at risk enrolled & 6,732 & 22,667 & 19,225 \\
Environmental benefits & 216,378 & 682,643 & 606,729 \\
\hline $\begin{array}{l}\text { Total budget } \\
\text { Efficiency (environmental } \\
\text { benefits/opportunity cost) }\end{array}$ & .08 & $\$ 2,550,596$ & $\$ 1,713,509$ \\
\hline
\end{tabular}

Table 6: Payments per hectare at risk of deforestation

\begin{tabular}{lccc}
\hline & Flat payment & $\begin{array}{c}\text { Opportunity cost } \\
\text { for forest at risk }\end{array}$ & $\begin{array}{c}\text { Opportunity cost for } \\
\text { forest at risk with } \\
\text { highest environmental } \\
\text { benefit per opportunity } \\
\text { cost } \\
C\end{array}$ \\
\hline $\begin{array}{l}\text { Mean payment per hectare at } \\
\text { risk }\end{array}$ & $\$ 7,610$ & $R_{c}$ & $\$ 96$ \\
$\begin{array}{l}\text { Minimum payment per hectare } \\
\text { at risk }\end{array}$ & $\$ 34$ & $\$ 5$ & $\$ 86$ \\
$\begin{array}{l}\text { Maximum payment per hectare } \\
\text { at risk }\end{array}$ & $\$ 654,222$ & $\$ 331$ & $\$ 5$ \\
\hline
\end{tabular}


Table 7. Distribution of payments from schemes $F$ and $C$ over ejido size and poverty classes

\begin{tabular}{|c|c|c|c|c|c|c|c|}
\hline \multirow[t]{2}{*}{ Area and Distance classes } & \multicolumn{2}{|c|}{$\begin{array}{l}\text { Participation } \\
\text { rate }\end{array}$} & \multicolumn{2}{|c|}{$\begin{array}{l}\text { Average payment per } \\
\text { community }\end{array}$} & \multicolumn{2}{|c|}{ Efficiency } & $\begin{array}{c}\text { Percentage } \\
\text { of overall } \\
\text { budget }\end{array}$ \\
\hline & $F$ & C & $F$ & $C$ & $F$ & $C$ & $C$ \\
\hline
\end{tabular}

Area:

$\begin{array}{lcccccccc}1^{\text {st }} \text { quartile - } & 97 & 43 & \$ 3,216 & \$ 1,006 & .04 & .39 & 11 & 2 \\ 2^{\text {nd }} \text { quartile - } & 91 & 50 & \$ 6,748 & \$ 3,371 & .04 & .29 & 23 & 10 \\ 3^{\text {rd }} \text { quartile }- & 88 & 67 & \$ 9,698 & \$ 4,054 & .08 & .35 & 33 & 16 \\ 4^{\text {th }} \text { quartile }- & 74 & 71 & \$ 11,300 & \$ 17,325 & .14 & .36 & 32 & 72\end{array}$

Poverty:

\begin{tabular}{lllllllll} 
Non-poor - & 85 & 50 & $\$ 120$ & $\$ 135$ & .06 & .30 & 46 & 39 \\
Poor - & 89 & 63 & $\$ 120$ & $\$ 51$ & .10 & .39 & 54 & 61 \\
\hline
\end{tabular}

The thresholds for the area quartiles are 1,240,2,270, and 5,160 hectares. The distance threshold is 27 kilometers. The threshold level for the poor is $53 \%$ of the population predicted to receive Progresa.

Table 8. Prediction equations for deforestation Dependent variable: Hectares of forest lost between 1994-2000

\begin{tabular}{lcc}
\hline Variable & $\begin{array}{c}(1) \\
\text { Parsimonious } \\
\text { specification }\end{array}$ & $\begin{array}{c}(2) \\
\text { Full specification }\end{array}$ \\
\hline Total area of the ejido in hectares & 0.01 & 0.01 \\
& $(0.91)$ & $(1.22)$ \\
Hectares of forest in 1994 & 0.09 & 0.09 \\
Forest squared & $(3.58)^{* *}$ & $(3.58)^{* * *}$ \\
Forest cubed & $-3 \times 10-^{6}$ & $-3 \times 10^{-6}$ \\
Percentage of total area in forest, 1994 & $(2.95)^{*}$ & $(2.98)^{* *}$ \\
& $3 \times 10^{-11}$ & $3 \times 10^{-11}$ \\
Average distance to forested area & $(2.41)^{*}$ & $(2.95)^{*}$ \\
Average slope of forested area & -20.1 & -18.5 \\
& $(2.50)$ & $(2.25)$ \\
& -3.4 & -9.9 \\
& $(0.29)$ & $(0.83)$ \\
& -6.9 & -8.6 \\
& $(0.75)$ & $(0.93)$
\end{tabular}


Average altitude of forested area in meters $\quad-0.09$

$-0.12$

(1.45)

$(1.89)$

Average distance*averagc slope

$-1.1$

$-1.2$

$(1.20)$

Average distance*average altitude

(1.36)

0.02

(1.91)

(1.91)

Ejido practices forestry

84.7

94.8

(1.16)

(1.17)

Number of ejidatarios in 1990

$-0.31$

0.28

(1.06)

Number of ejidatarios squared

$9 \times 10^{-5}$

$(0.81)$

Distance to nearest city in kilometers

$-0.30$

$(0.77)$

$-0.32$

$(0.72)$

Average number of people per hh with secondary

$-198.26$

education

$(2.38)^{*}$

Average parcel size of ejidatarios in hectares

$-1.95$

$(1.83)^{*}$

Number of ejidatarios* Gini coefficient of private

$-1.06$

parcels

Membership ratio*forestry cjido

$-39.70$

(0.44)

$-4.75$

Ratio of members to total population in ejido

$(3.04)^{* *}$

Gini coefficient of private parcels

$-206.9$

(1.53)

Predicted proportion of population receiving Progresa

$-144.2$

$(0.40)$

Constant

145.34

704.84

(1.21)

$(2.70)^{* *}$

Obscrvations

395

395

Adjusted R-squared

0.38

0.42

Robust $t$-statistics in parentheses. ${ }^{*}$ significant at $5 \%$ level; ${ }^{* *}$ significant at $1 \%$ level 
Table 9. Summary of payments and participants in predicted deforestation program

\begin{tabular}{lc}
\hline Payment rule & $\begin{array}{c}\text { Specification } \\
(\mathbf{1})\end{array}$ \\
\hline $\begin{array}{l}\text { Percent of participating } \\
\text { cjidos }\end{array}$ & 50 \\
$\begin{array}{l}\text { Average payment per } \\
\text { participating ejido }\end{array}$ & $\$ 8,744$ \\
$\begin{array}{l}\text { Median payment per } \\
\text { participating ejido }\end{array}$ & $\$ 2,058$ \\
$\begin{array}{l}\text { Gini coefficient of } \\
\text { payments over } \\
\text { participants } \\
\text { Total hectares enrolled }\end{array}$ & .77 \\
$\begin{array}{l}\text { Hectares at risk } \\
\text { enrolled }\end{array}$ & $1,197,210$ \\
Environmental benefits & $1,757,652$ \\
Total budget & .15 \\
$\begin{array}{l}\text { Efficiency } \\
\text { (environmental } \\
\text { benefits/opportunity } \\
\text { cost) }\end{array}$ & .009 \\
\hline
\end{tabular}


Table 10. Errors in payment distribution result from predictions

\begin{tabular}{lccc}
\hline Characteristics & $\begin{array}{c}\text { Didn't receive } \\
\text { payments but } \\
\text { should have } \\
\text { (Type I) }\end{array}$ & $\begin{array}{c}\text { Received } \\
\text { payments and } \\
\text { should have }\end{array}$ & $\begin{array}{c}\text { Received } \\
\text { payments and } \\
\text { shouldn't have }\end{array}$ \\
\hline $\begin{array}{l}\text { Number } \\
\text { Total size in hectares }\end{array}$ & 121 & 109 & 92 \\
Hectares of forest, 1993 & 5,106 & 10,872 & 2,647 \\
$\begin{array}{l}\text { Average deforestation rate } \\
\text { Predicted deforestation rate }\end{array}$ & .029 & 9,567 & 1,678 \\
$\begin{array}{l}\text { Predicted proportion of } \\
\text { Progresa recipients }\end{array}$ & .014 & .010 & .016 \\
$\begin{array}{l}\text { Average environmental } \\
\text { benefits per hectare }\end{array}$ & 30.2 & .014 & .53 \\
$\begin{array}{l}\text { Avcrage opportunity cost } \\
\text { per hectare }\end{array}$ & $\$ 105$ & .54 & $\$ 66$ \\
\hline
\end{tabular}

